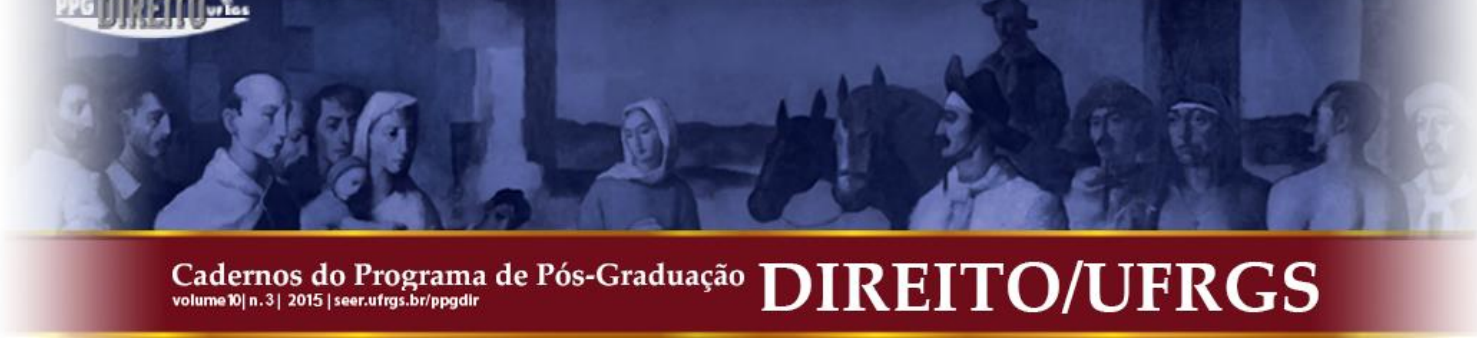

\title{
A AUSÊNCIA DE EFICÁCIA DO DIREITO FUNDAMENTAL À SAÚDE E A VULNERABILIDADE DAS PESSOAS QUE DEPENDEM DA SAÚDE PÚBLICA: ONDE ESTÁ A INVIOLABILIDADE DA DIGNIDADE HUMANA?
}

\author{
THE LACK OF EFFECTIVENESS OF THE FUNDAMENTAL RIGHT TO HEALTH AND \\ THE VULNERABILITY OF PEOPLE WHO DEPEND ON PUBLIC HEALTH SERVICES: \\ WHERE IS THE INVIOLABILITY OF HUMAN DIGNITY?
}

Cleide Fermentão* Pedro Henrique Sanches Aguera**

\begin{abstract}
Resumo: Neste ensaio, inicialmente aborda-se o desenvolvimento de conceitos de pessoa e de indivíduo que aqui são utilizados. Dessa forma, é correto afirmar a dignidade da pessoa humana e não a dignidade do indivíduo. Também se fundamenta que a finalidade principal do Direito é a proteção dos valores humanos, porque a pessoa humana é centro do Direito, e, portanto, deve ser respeitada a sua dignidade. Depois, afirma-se que a segunda geração de direitos fundamentais corresponde aos direitos sociais, econômicos e culturais, estando ligada diretamente a direitos prestacionais sociais do Estado perante o indivíduo. A segunda geração difere das demais gerações pelo fato de o Estado passar a ter a obrigação de possibilitar à pessoa humana o seu desenvolvimento. A Constituição Federal brasileira de 1988 regulamentou os direitos de segunda geração, incluindo o direito à saúde como um direito social. É a saúde um direito fundamental de segunda geração e, ao mencionar o dispositivo que ele é um direito de todos, é ele tanto um direito individual como coletivo. Há o dever fundamental de prestação de saúde por parte do Estado, inclusive com a formulação de políticas públicas, devendo o Estado criar meios para que todos possam usufruir do mesmo. Na medida em que ficou determinado pelo constituinte um sistema universal de acesso aos serviços públicos de saúde, foi reforçada a ideia de responsabilidade solidária entre os entes da federação. Surge o problema aqui apontado das questões ligadas à implementação e à manutenção das políticas públicas de saúde já existentes. Estando a dignidade da pessoa humana ligada aos direitos fundamentais de segunda geração e sendo ela o princípio norteador do ordenamento jurídico, poderia-se imaginar que qualquer pessoa teria sua dignidade garantida, se tivesse seus direitos sociais assegurados, incluído o direito à saúde.
\end{abstract}

Abstract: In this essay, initially it is addressed the development of the concepts of person and individual that are used here. Thus, it is correct to affirm the dignity of the human person and not the dignity of the individual. Also, it is justified that the main purpose of the Law is the protection of human values, because the human person is the center of the Law, and therefore its dignity must be respected. Then it is said that the second generation of fundamental rights corresponds to the social, economic, and cultural rights, being bound directly to social rights to State positive actions to the individual. The second generation differs from other generations by the fact the State go on to have a duty to enable the human person to develop. The Brazilian Federal Constitution of 1988 regulates the rights of second generation, including the right to health as a social right. The right to health is a fundamental right of second generation, and, by stating a constitutional clause that it is a right for everyone, it is both an individual and collective right. There is the fundamental duty of providing health care by the State, including the elaboration of public policies, and the State must provide for everyone to avail themselves of it. In the extent that the constituent determined a universal system of access to public health services, the idea of joint liability between the federal entities has been reinforced. The problem here pointed of the issues associated with implementation and maintenance of existing public health policies arises. Being human dignity bound to the fundamental rights of second generation, and being it the guiding principle of the legal system, one would imagine that anyone would have guaranteed their dignity if they had their social rights, including the right to health, ensured.

\footnotetext{
* Doutora em Direitos Sociais pela Universidade Federal do Paraná (UFPR). Mestre em Direito Civil pela Universidade Estadual de Maringá, Paraná (UEM). Professora do Programa de Mestrado, Especialização e Graduação do Centro Universitário de Maringá, Paraná (Unicesumar), e da Faculdade Metropolitana de Maringá, Paraná (Famma).

** Mestrando do Programa de Pós-Graduação em Ciências Jurídicas (PPGCJ) do Centro Universitário de Maringá, Paraná (Unicesumar), com bolsa CAPES. Pós-Graduado em Direito Processual Civil pela Faculdade de Direito Damásio de Jesus. Pós-Graduado em Direito Empresarial pelo Centro Universitário de Maringá, Paraná (Unicesumar).
} 


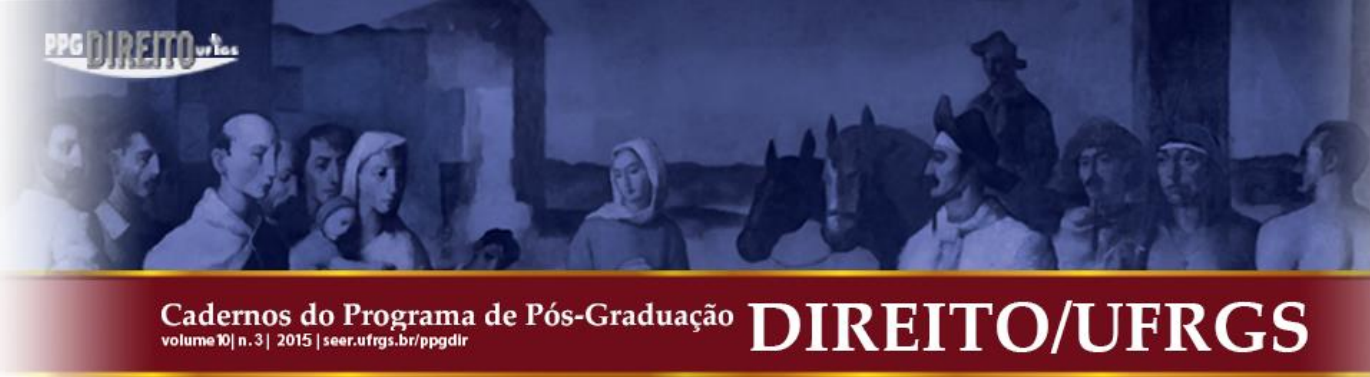

Neste trabalho científico, foi utilizado o método teórico que consiste na pesquisa de obras e artigos de periódicos especializados que tratam do assunto.

\title{
1 INDIVÍDUO E PESSOA DETENTORES DO DIREITO À SAÚDE
}

\subsection{Indivíduo}

A origem do termo indivíduo pode ser encontrada inicialmente no contexto medieval. Hespanha assim estabelece a relação acerca da origem do surgimento do paradigma individualista:

Embora se lhe possam encontrar antecedentes mais recuados (oposição entre estóicos a aristotélicos, entre agostinianismo e tomismo), a genealogia mais direta do paradigma individualista da sociedade e do poder deve-se buscar na escolástica franciscana quatrocentista [Duns Scotto (1266 - 1308), Guilherme d Occam (13001350]. ${ }^{1}$

Posteriormente, em Immanuel Kant, o conceito de indivíduo se comunica à definição de liberdade, por meio da noção de autonomia da vontade, entendendo como a independência da ética do ser humano.

\begin{abstract}
A vontade é uma espécie de causalidade dos seres vivos enquanto racionais, e liberdade seria a propriedade desta causalidade, pela qual ela pode ser eficiente, independentemente de causas estranhas que a determinem; assim como necessidade natural é a propriedade da causalidade de todos os seres irracionais de serem determinados à atividade pela influência de causa estanhas ${ }^{2}$.
\end{abstract}

A autonomia é a possibilidade de o ser humano ser racional. Opõe-se com isso a uma concepção antropológica que identifica o ser humano simplesmente pela teoria da natureza. Dessa forma, a autonomia é a autolegislação pela pura razão.

Em relação a este aspecto, Kant analisa a autonomia da vontade como a faculdade de dar a si mesmo sua própria lei. É a autonomia que explica por que o indivíduo deve sujeitar-se à lei moral, pois esta obriga o indivíduo porque é produzida pelo próprio agente como ser

${ }^{1}$ HESPANHA, António Manuel. O direito dos letrados no império português. Florianópolis: Fundação Boiteux, 2006, p.33.

${ }^{2}$ KANT, Immanuel. Fundamentação da Metafísica dos Costumes. Lisboa: Edições 70, 2007, p. 93.

Cadernos do Programa de Pós-Graduação em Direito PPGDir./UFRgS | Edição Digital | Porto Alegre | Volume X | Número 3 | 2015 | P. 112 - 128 


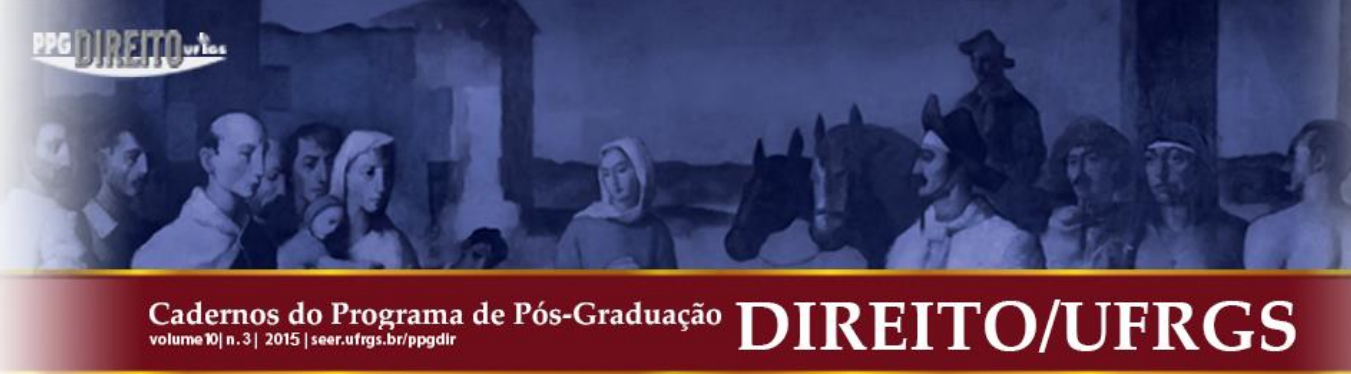

autônomo. É também dever da autonomia distinguir o ser humano dos demais seres vivos, atribuindo-lhe uma dignidade. Com este fundamento o ser humano seria um fim em si mesmo, isto é, não poderia ser instrumentalizado como meio para quaisquer fins.

Com estímulo nessa teoria surge a noção de indivíduo que constantemente é mencionada. Antes do século XVIII, a noção de indivíduo praticamente não existia, pois os seres humanos eram vistos na medida de cada grupo e de cada época, apenas como pessoa. Em outras palavras, o indivíduo era tratado na proporção em que interessava economicamente e politicamente para o grupo social. Dessa forma, se o fosse era considerado uma pessoa, senão ele se tornava um objeto, uma coisa, um instrumento.

Todas as pessoas são iguais e assim devem ser tratadas. E cada indivíduo é único, caracterizado pela sua história, sua vontade e sua biografia. As especificações de cada indivíduo constituem seu diferencial; as particularidades de sua personalidade e da sua liberdade de ser.

Os direitos da personalidade que cada pessoa tem por seus atributos personalíssimos, são direitos de cada indivíduo por pertencerem exclusivamente a cada individuo. Dito de outro modo: todas as pessoas possuem direitos da personalidade, mas cada indivíduo possui os seus próprios, únicos e exclusivos.

\subsection{Pessoa}

O termo pessoa indica no sentido técnico-jurídico atual, "todo ser, capaz ou suscetível de direitos e obrigações" ${ }^{3}$. Dessa forma, sujeito das relações jurídicas e, como tal, possuidor de direitos e deveres.

A palavra pessoa vem do latim persona que significa "máscara de teatro". Origina-se do teatro grego da Antiguidade, onde os personagens gregos do drama encenado se diferenciavam pelas máscaras utilizadas. Em outras palavras, o conceito de pessoa traz a ideia de representação social, do desempenho de um papel social, o papel a ser representado por aquele que está utilizando a máscara. Numa evolução conceitual, o termo persona passou a designar o próprio ator, personagem. Por certo, não existe termo mais apropriado para qualificar o homem do que o termo persona. Para Tomás de Aquino, ${ }^{4}$ designa aquilo que há

\footnotetext{
${ }^{3}$ SILVA, De Plácido e. Vocabulário Jurídico. 6. ed. Rio de Janeiro: Forense, 1980, p. 1.157.

${ }^{4}$ AQUINO, Tomás de. Suma Teológica. São Paulo: Loyola, 2003, p. 29.

Cadernos do Programa de Pós-Graduação em Direito PPGDir./UFRgS | Edição Digital | Porto Alegre | Volume X | Número 3 | 2015 | P. 112-128
} 


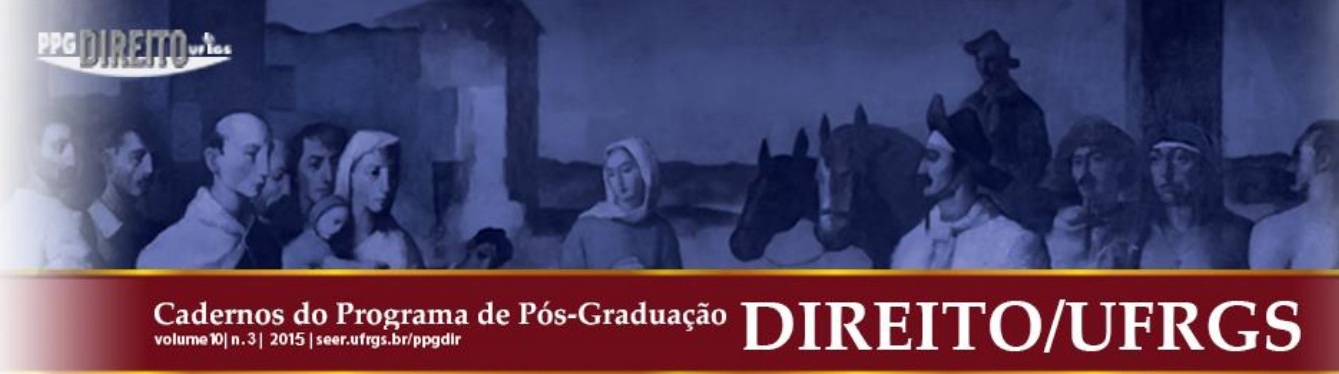

de mais perfeito no universo. Para ele, persona significa que é mais perfeito em toda a natureza, isto é, um indivíduo subsistente de natureza racional.

Ao decorrer da história, as leis já eram familiarizadas com o termo de pessoa. Pois na relação social, em todos os tempos, persistiu a necessidade da interação e do desenvolvimento de papéis sociais. No Brasil, no período pré-republicano, verifica-se um claro relato de exclusão da pessoa negra escrava que, para o direito penal, eram consideradas pessoas e, para o direito civil, consideradas apenas um objeto. Isto é, na área criminal esperava-se um comportamento, um portar-se de determinada maneira, existindo desta forma um papel a ser desempenhado. Por outro lado, no âmbito civil, onde prevaleciam as relações privadas, não tinha papel nenhum a desempenhar, considerado uma coisa, suscetível à apropriação pelos brancos.

Esse conceito foi atribuído tanto na sociedade antiga, como na sociedade contemporânea, em que existe maior mobilidade social. Consequentemente, o reflexo de pessoa apresenta-se como uma noção perfeita para a contemporaneidade, já que se trata de uma formulação voltada para uma dimensão massificada da existência social.

Para Miguel Reale, existe uma construção filosófica entre homem e dignidade. Para ele é “dessa autoconsciência que nasce a ideia de pessoa, segundo a qual não se é homem pelo mero fato de existir, mas pelo significado ou sentido da existência"5. Nesse sentido não tem como diferenciar o conceito de pessoa e homem, visto que estão interligados. Na análise de Hannah Arendt, "homem é genérico, podendo referir a qualquer homem, enquanto pessoa

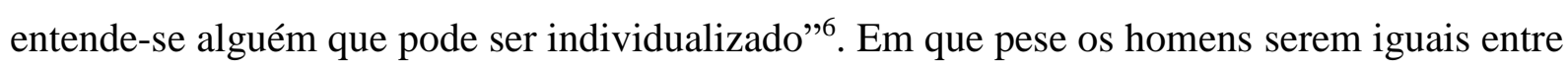
si, quando falam ou agem se distinguem uns dos outros como sendo seres únicos. Com voz, fisionomia e palavras que inauguram uma pessoa única no mundo.

Para Hannah Arendt, os homens são indistintos, não possuindo singularidade, ao passo que a pessoa é um ser único dotado de individualidade intransponível. "A pluralidade é a condição da ação humana pelo fato de sermos todos os mesmos, isto é, humanos, sem que ninguém seja exatamente igual a qualquer pessoa que tenha existido, exista ou venha a existir"7. O homem é um ser indivisível, composto de corpo e espírito, é um sujeito soberano,

\footnotetext{
${ }^{5}$ REALE, Miguel. Filosofia do Direito. 17. ed. São Paulo: Saraiva, 1996, p. 211.

${ }^{6}$ ARENDT, Hannah. Homens em tempos sombrios. Tradução de Denise Bottmann. São Paulo: Companhia das Letras, 2008, p. 78.

7 ARENDT, Hannah. A condição humana. Tradução Roberto Raposo. 10. ed. Rio de Janeiro: Forense Universitária, 2009, p. 16.
}

Cadernos do Programa de Pós-Graduação em Direito PPGDir./UFRgS | Edição Digital | Porto Alegre | Volume X | Número 3 | 2015 | P. 112 -128 


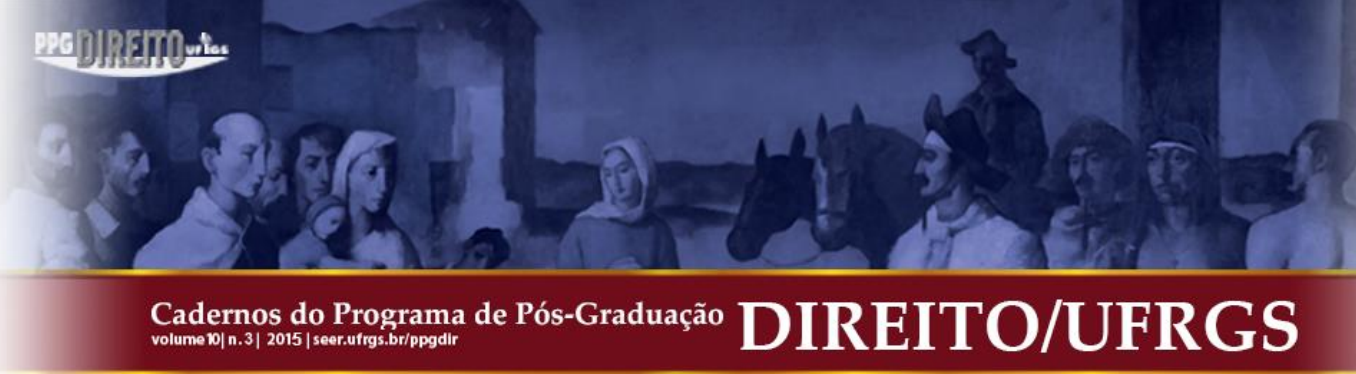

dotado da potência do Verbo. Enfim, é uma pessoa, um espírito encanado ${ }^{8}$. Por tudo isso, a dignidade da pessoa humana independente das condições singulares de cada individuo. Dessa forma é correto afirmar a dignidade da pessoa humana e não a dignidade do indivíduo. Independentemente da representação social que cada pessoa possua, isto é, pela simples razão de ser uma pessoa humana é dotada de dignidade, e assim deve ser tratada, sobretudo pelo ordenamento jurídico.

No universo não existe nenhum outro ser racional como o homem, por esta razão ele, e somente ele, é pessoa. Os demais seres, por mais que cumpram sua finalidade natural, nem assim se igualam ao homem. O homem possui a dimensão da liberdade que lhe permite escolher, de forma racional, quanto ao seu desígnio, podendo afasta-se ou aproximar-se do seu fim maior. Portanto, a finalidade principal do Direito é a proteção dos valores humanos, porque a pessoa humana é centro do Direito, e, portanto, deve ser respeitada a sua dignidade.

\section{DIREITO À SAUDE COMO DIREITO FUNDAMENTAL SOCIAL DE $2^{\circ} 117$ GERAÇÃO}

A segunda geração de direitos fundamentais corresponde aos direitos sociais, econômicos e culturais, estando ligada diretamente a direitos prestacionais sociais do Estado perante o indivíduo. A segunda geração difere das demais gerações pelo fato de o Estado passar a ter a obrigação de possibilitar à pessoa humana o seu desenvolvimento.

O caráter de liberdade negativa estabelecida na primeira dimensão se deu em razão de afastar o Estado para que a liberdade fosse exercida. Já na segunda dimensão, o Estado tem a obrigação em concretizar e efetivar a proteção e o desenvolvimento da pessoa humana. $\mathrm{O}$ Estado pode diretamente atuar em prol destes direitos ou simplesmente ensejar a participação de outras instituições, com o proposito de concretiza-1o 9 .

Themistocles Brandão analisa o surgimento desta geração:

O começo do século viu a inclusão de uma nova categoria de direitos nas declarações e, ainda mais recentemente, nos princípios garantidores da liberdade das nações e das normas da convivência internacional. Entre os direitos chamados

\footnotetext{
${ }^{8}$ SUPIOT, Alain. Homo juridicus: ensaio sobre a função antropológica do Direito. Tradução de Maria Ermantina de Almeida Prado Galvão. São Paulo: Martins Fontes, 2007, p. 15.

${ }^{9}$ FACHIN, Zulmar. Teoria Geral do Direito Constitucional. 2. ed. Londrina: IDCC, 1997, p. 65.
} 


\section{Mag)

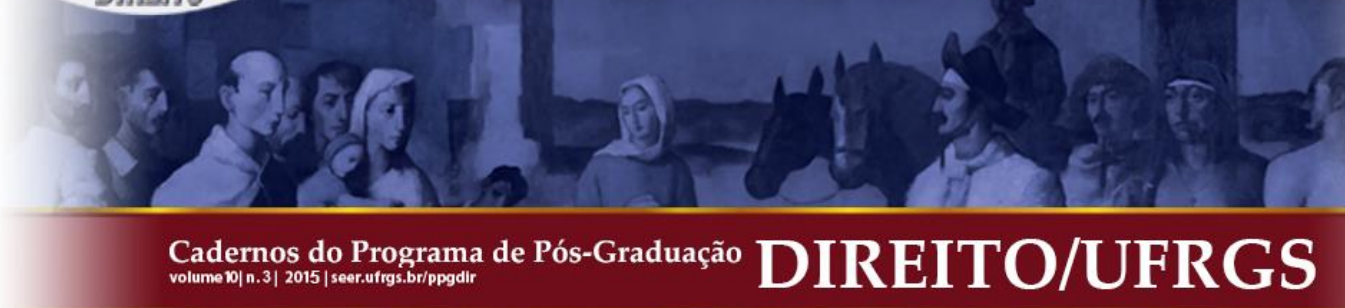

anteriores, que tratavam apenas de previdência social, a atual instituiu um sistema mais abrangente. Além de terem sido criados novos direitos, foram constitucionalizados muitos direitos que já existam na legislação infraconstitucional. ${ }^{11}$

É possível verificar que foi dada uma relevante importância ao direito à saúde, principalmente considerando o fato de estar intimamente atrelado ao direito à vida, manifestando a proteção constitucional à dignidade da pessoa humana. A lei constitucional não faz qualquer menção ao tipo de saúde que é garantida a proteção, possibilitando o entendimento de que a tutela do Direito à saúde apresentaria duas faces - uma de preservação e outra de proteção. Enquanto a preservação da saúde se relacionaria às políticas de redução de risco de uma determinada doença, numa órbita genérica, a proteção à saúde se caracterizaria como um direito individual, de tratamento e recuperação de uma determinada pessoa. Há que demonstrar, ainda, que o Direito à saúde é Direito de todos e dever do Estado, e deve ser garantido por meio de políticas sociais e econômicas que visem à redução do risco de doença e de outros agravos. É o que dispões o artigo 196 da Constituição Federal ${ }^{12}$.

No que diz respeito à interpretação do referido artigo constitucional, entende-se que, primeiramente, ao mencionar ser um direito de todos, entende-se como um direito tanto individual como coletivo, sendo considerado um dever do Estado, em que, além de ser um direito fundamental, há o dever fundamental de prestação de saúde por parte do Estado. No que confere às políticas sociais e econômicas, fica ressalvada a necessidade de formulação de políticas públicas que concretizem o direito à saúde visando sempre a redução do risco de doenças e outros agravos de forma a evidenciar sua dimensão preventiva. Ficou, ainda, determinado pelo constituinte um sistema universal de acesso aos serviços públicos de saúde, reforçando a ideia de responsabilidade solidária entre os entes da federação ${ }^{13}$.

É possível argumentar que a disposição acerca do direito à saúde se insere no contexto de direitos fundamentais com o intuito de colaborar com a proteção necessária ao princípio da dignidade da pessoa humana, existindo como um dos serviços públicos mais importantes e necessários ao ordenamento jurídico pátrio.

\footnotetext{
${ }^{11}$ FACHIN, Zulmar. Teoria Geral do Direito Constitucional. 2. ed. Londrina: IDCC, 1997, p. 98.

${ }^{12}$ BRASIL. Constituição da República Federativa do Brasil de 1988. Art. 196. A saúde é direito de todos e dever do Estado, garantido mediante políticas sociais e econômicas que visem à redução do risco de doença e de outros agravos e ao acesso universal e igualitário às ações e serviços para sua promoção, proteção e recuperação.

${ }^{13}$ MENDES, Gilmar Ferreira; BRANCO, Paulo Gustavo Gonet. Curso de Direito Constitucional. 9. ed. São Paulo: Saraiva, 2014, p. 643-644.
}

Cadernos do Programa de Pós-Graduação em Direito PPGDir./UFRgS | Edição Digital | Porto Alegre | Volume X | Número 3 | 2015 | P. 112-128 


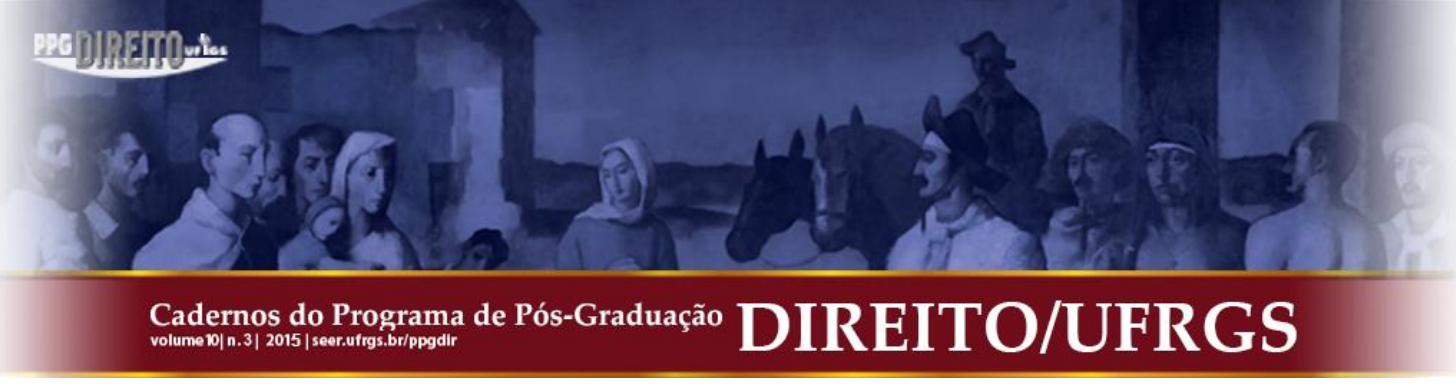

A competência para legislar acerca da proteção e defesa da saúde engloba a união, estados e distrito federal, conforme previsão expressa no artigo 24, XII, da Constituição Federal. No que confere a competência executiva, incluirá nesse rol os municípios, conforme mencionado no próprio artigo 23, II da Constituição.

Os problemas existentes no Brasil, ligados a saúde, não são todos derivados da falta de legislação específica, mas mais propriamente da falta de aplicabilidade de tais normas. As questões ligadas à implementação e à manutenção das políticas públicas de saúde já existentes não são eficazes, tornando todo o sistema de proteção constitucional à saúde lúdico para os legisladores e ligeiramente falho para a sociedade como um todo.

De modo geral, ao se considerar o Direito constitucional à saúde existente no ordenamento jurídico pátrio e as medidas de efetivação, fica claro que o maior problema existente não está na legislação atribuída, e, portanto, o direito a saúde deve se efetivar mediante ações especificas (dimensão individual) e mediante amplas políticas públicas com a intenção de diminuição no risco de doença e de outros agravos ${ }^{14}$. De todo o modo, a saúde é um direito social previsto constitucionalmente no artigo $6^{\circ}$ e no artigo 19 da Constituição Federal de 1988, sendo norma de ordem pública, imperativa e inviolável, cabendo ao Estado concretizar tal direito. Em razão disso, os problemas existentes na ausência de concretização desse direito fundamental, ocorrem em razão da ausência de aplicabilidade da norma, e a aplicação da mesma é de responsabilidade do Estado.

A falta de eficácia das normas existentes em defesa da pessoa humana em sua saúde é materializada pela falta de leitos em hospitais, ausência de equipamentos necessários para tratamentos específicos, falta de médicos e medicamentos. Pessoas estão perecendo em portas de hospitais ou sendo atendidas em corredores, sem a condição necessária de tratamento, o que fere o dispositivo constitucional e a dignidade humana ${ }^{15}$.

\footnotetext{
${ }^{14}$ MENDES, Gilmar Ferreira. BRANCO, Paulo Gustavo Gonet. Curso de Direito Constitucional. 9 ed.rev. e atual. São Paulo: Saraiva, 2014. p. 644.

${ }^{15}$ PERNAMBUCO. Tribunal de Justiça. Apelação/Reexame Necessário. REEX 10066320108170480 PE 0001006-63.2010.8.17.0480 (TJ-PE). Ementa: CONSTITUCIONAL. ADMINISTRATIVO. PROCESSUAL CIVIL. REEXAME NECESSÁRIO E APELAÇÃO CÍVEL. AÇÃO DE INDENIZAÇÃO POR DANOS MORAIS. RESPONSABILIDADE CIVIL DO MUNICÍPIO DE CARUARU. ALEGAÇÃO DE QUE A MORTE DA PACIENTE DECORREU DA AUSÊNCIA DE LEITO NA REDE PÚBLICA. FALTA DE ATENDIMENTO ADEQUADO EM HOSPITAL MUNICIPAL. FALHA NO ATENDIMENTO. COMPROVADO. TEORIA DA PERDA DE UMA CHANCE. INDENIZAÇ̃̃O POR DANOS MORAIS. RECONHECIDA. REEXAME NECESSÁRIO PROVIDO PARCIALMENTE. DECISÃO UNÂNIME.
}

Cadernos do Programa de Pós-Graduação em Direito PPGDir./UFRgS | Edição Digital | Porto Alegre | Volume X | Número 3 | 2015 | P. 112 -128 


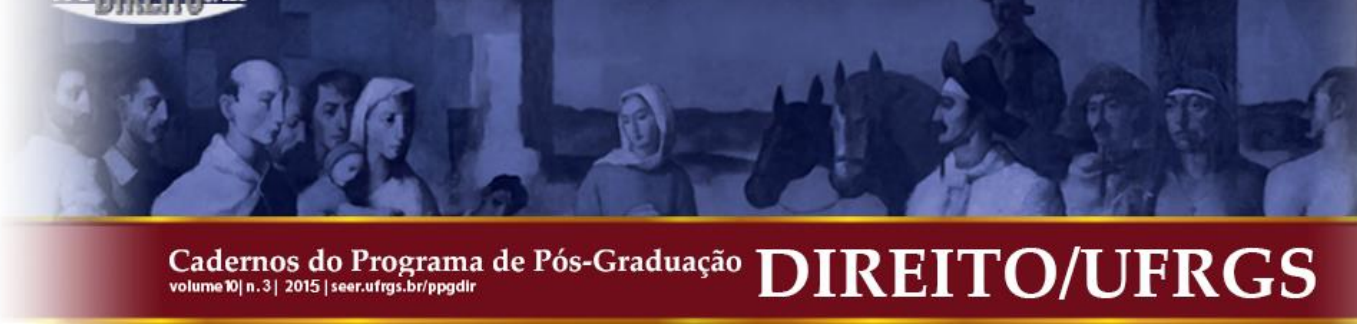

\section{DIGNIDADE DA PESSOA HUMANA, DIREITO DA PERSONALIDADE E O DIREITO À SAÚDE}

A Constituição Federal de 1988 positivou o principio da dignidade da pessoa humana em seu art. $1^{\circ}$, inciso III, considerando uma cláusula geral de concreção e do desenvolvimento da personalidade do indivíduo. Para tanto adquire aparência axiológica, sendo utilizado como alicerce onde transita o sistema fundamental e a estruturação do Estado brasileiro.

Szaniawski ${ }^{16}$ aponta que os direitos da personalidade não se esgotam no art. $5^{\circ}$ da Constituição Federal e que há outras colunas de sustentação do sistema jurídico como: o principio fundamental de toda a pessoa possuir um patrimônio mínimo, previsto no título II, art. $5^{\circ}$, inciso XXII, e no titulo VII, capítulos II e III; e os demais princípios, consagrados no título VIII, garantindo, no capítulo II, a toda pessoa, o exercício do direito à saúde; no capitulo VI, o direito ao meio ambiente ecologicamente equilibrado, a fim de poder exercer seu direito à vida com o máximo de qualidade de vida; e, no capítulo VII, o direito de possuir uma família e de planejá-la, de acordo com o principio da dignidade humana e da paternidade responsável.

A doutrina brasileira vem aceitando a classificação tripartida dos direitos da personalidade, agrupados da seguinte forma: (a) direito à integridade física, compreendendo: o direito à vida e aos alimentos; o direito sobre o próprio corpo vivo; o direito sobre o próprio corpo morto; o direito sobre o corpo alheio vivo; (b) direito à integridade intelectual, que compreende: o direito à liberdade de pensamento; e (c) direito à integridade moral com as seguintes tipificações: direito à liberdade civil, política e religioso; direito à imagem e o direito à identidade pessoal, familiar e social.

O princípio da dignidade humana no ordenamento jurídico pátrio é considerado um dos princípios constitucionais de maior importância, tendo em vista que emanam dele todos os direitos fundamentais do ser humano, entende-se relevante examiná-lo com mais precisão. Tem seu berço secular na filosofia. Com fundamentação na ética, na filosofia moral, a

\footnotetext{
${ }^{16}$ SZANIAWSKI, Elimar. Direitos da Personalidade e sua Tutela. 2. ed. ver., atual. e ampl. São Paulo: Editora
} Revista dos Tribunais, 2005. p. 138. 


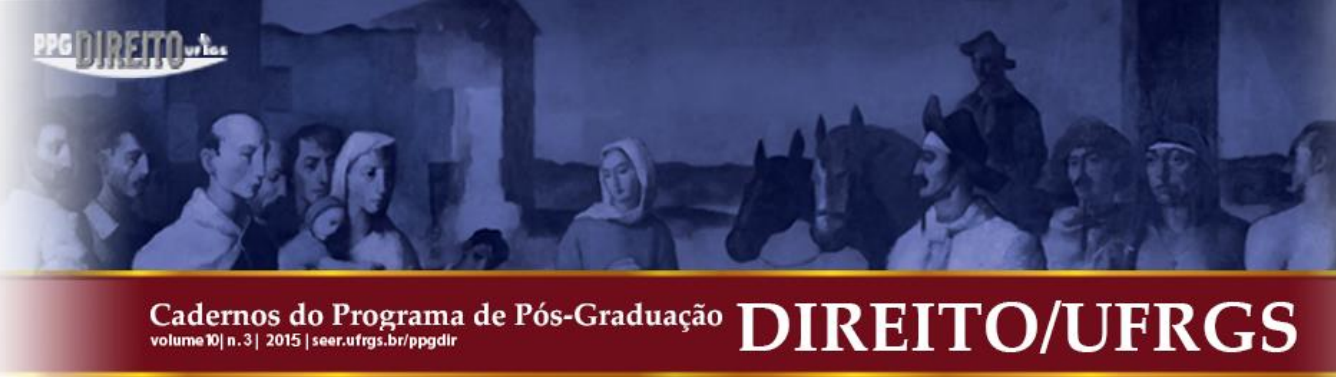

O conteúdo do principio da dignidade é apresentado em dois momentos. Inicialmente, a dignidade é responsável pela proteção da pessoa humana no que diz respeito à sua integridade. Em segunda percepção, o princípio assume a ideia de a pessoa ser respeitada como ser intelectual. Sobe o enfoque da saúde, é importante analisarmos o primeiro prisma ${ }^{21}$. Dessa forma, a dignidade da pessoa humana é o princípio norteador do ordenamento jurídico, que serve para fundamentar os demais princípios e normas nacionais, como alicerce. Por essa coordenação, a dignidade da pessoa humana possui dupla natureza, vista como um postulado normativo, em razão de servir para apontar a forma em que as demais normas devem ser feitas e aplicadas, sendo que nenhuma norma pode ferir a dignidade da pessoa humana ${ }^{22}$.

Dessa união é que se poderia imaginar que qualquer pessoa teria sua dignidade garantida, se fosse assegurada seus direitos sociais. Assim, é notório que a própria constituição se pauta na direção da implementação da dignidade no meio social. A defesa da dignidade humana na área da saúde está em exigir do Estado a aplicabilidade da norma, proporcionando à pessoa humana o desenvolvimento físico e psíquico, que pode ser entendido como saúde.

\section{CONSIDERAÇÕES FINAIS}

Não obstante sua inclusão no texto constitucional, o direito social à saúde é fixado tanto com base na $2^{\circ}$ dimensão dos direitos fundamentais, como no principio basilar da dignidade da pessoa humana. A saúde, atualmente, é objeto de estudo nas diversas disciplinas do ordenamento jurídico. A consagração dos direitos sociais, o seu reconhecimento enquanto direito fundamental, leva à necessidade de aplicação máxima de seu texto. Especificamente, o que se refere como direito fundamental de segunda geração, propriamente dito o direito a saúde, caminha para o questionamento de uma série de dogmas, em especial aqueles que levam a um núcleo central: a autonomia, com efeito erga omnes e sua concretização no mundo dos fatos.

No plano formal e técnico, pode-se afirmar com propriedade que a legislação atual, no que se refere a direito à saúde, é referência no mundo todo. Entretanto, tal afirmação não se

\footnotetext{
${ }^{21}$ COING, H. Elementos Fundamentais da Filosofia do Direito. Trad. Elisete Antoniuk. Porto Alegre: Fabris, 2002, p. 246-247.

${ }^{22}$ LAFER, Celso. A Reconstrução dos Direitos Humanos. São Paulo: Cia das letras, 1988. p. 78. Cadernos do Programa de Pós-Graduação em Direito PPGDir./UFRgS | Edição Digital | Porto Alegre | Volume X | Número 3 | 2015 | P. 112 -128
} 


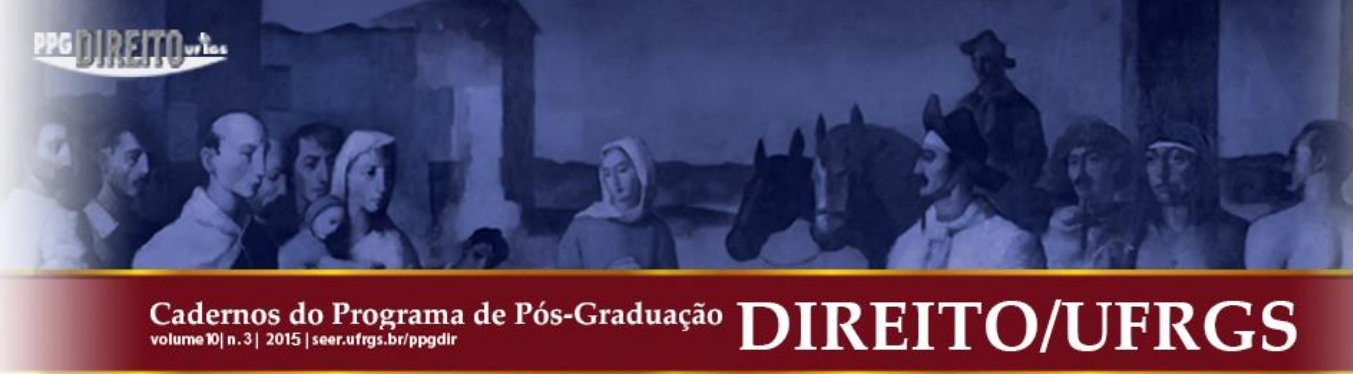

FACHIN, Zulmar. Curso de direito constitucional. 5. ed. Rio de Janeiro: Forense, 2012.

FACHIN, Zulmar; OLIVEIRA, Evaldo Dias de. Seguridade social como direito fundamental: garantia de efetivação na Constituição Brasileira. Scientia Iuris, Londrina, v. 15, n. 1, p. 175197, jun. 2011.

FRANÇA, Rubens Limongi. Instituições de direito civil. 3. ed. São Paulo: Saraiva, 1988.

FREUD, Sigmund. O ego e o id. Tradução de Jayme Salomão. Rio de Janeiro: Imago, 1974, v. 19.

MENDES, Gilmar Ferreira; BRANCO, Paulo Gustavo Gonet. Curso de Direito Constitucional. 9. ed. São Paulo: Saraiva, 2014.

HESPANHA, António Manuel. O direito dos letrados no império português. Florianópolis: Fundação Boiteux, 2006.

KANT, Immanuel. Fundamentação da metafísica dos costumes. Tradução de Leopoldo Halzbach. São Paulo: Martin Claret, 2003.

Fundamentação à metafisica dos costumes. Lisboa: Ediçõoies 70, 2005.

A Metafísica dos Costumes. Tradução de Edson Bini. Bauru: Edipro, 2003.

Fundamentação da Metafísica dos Costumes. Tradução de Paulo Quintela. Coleção Os Pensadores. São Paulo: Abril Cultural, 1980.

NUNES, Rizzato. O principio Constitucional da Dignidade da Pessoa Humana. São Paulo: Saraiva, 2002.

PLATÃO. A República. Tradução de M. H.R. Pereira. Lisboa: Fundação Calouste. Gulbenkian, 1993.

REALE, Miguel. Filosofia do Direito. 17. ed. Saraiva: São Paulo, 1996. 


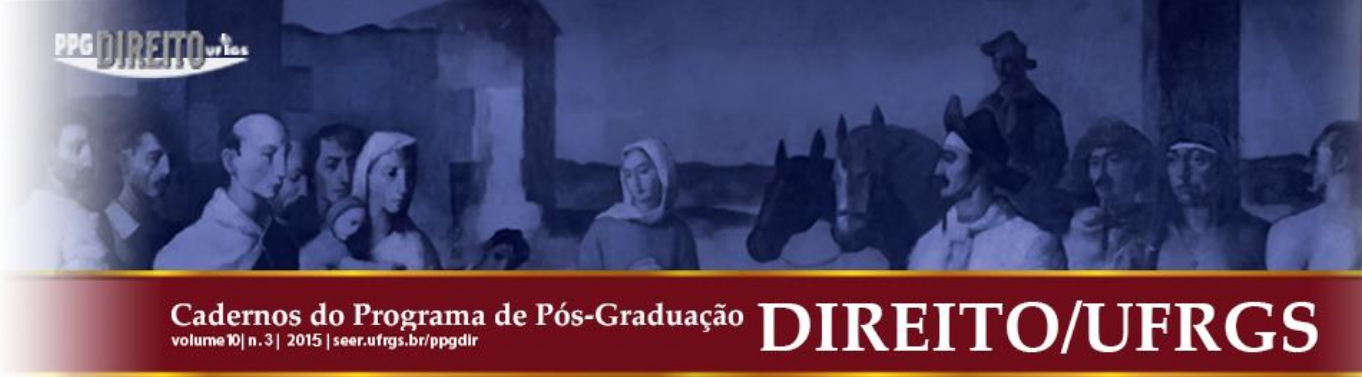

SARMENTO, Daniel. Direitos Fundamentais e Relações Privadas. 2. ed. Rio de Janeiro: Lumen Juris, 2010.

SARLET, Wolfgang Ingo. Dignidade da pessoa humana e direitos fundamentais na Constituição da República de 1988. Porto Alegre: Livraria do Advogado, 2002.

SILVA, De Plácido e. Vocabulário Jurídico. 6. ed. Rio de Janeiro: Forense, 1980.

SUPIOT, Alain. Homo juridicus: ensaio sobre a função antropológica do Direito. Tradução de Maria Ermantina de Almeida Prado Galvão. São Paulo: Martins Fontes, 2007.

SZANIAWSKI, Elimar. Direitos da Personalidade e sua Tutela. 2. ed. ver., atual. e ampl. São Paulo: Editora Revista dos Tribunais, 2005.

Submissão: 30/09/2015 Aceito para Publicação: 31/12/2015 
